\title{
A Novel PCB77 Electrochemical Sensor Based on Nano-functionalized Electrode and Selected Aptamer
}

\author{
Xuelian Yao ${ }^{1,2}$, Chadan $\mathrm{Chen}^{2}$, Lin $\mathrm{Chen}^{2}$, Xiong $\mathrm{Wei}^{2}$, Hanfeng Cui ${ }^{2}$, Hanlin $\mathrm{Xu}^{1,{ }^{*}}$ and Hao Fan ${ }^{2, \dagger}$ \\ ${ }^{1}$ Department of Pharmacy, Hubei University of Chinese Medicine, Wuhan 430065, China \\ ${ }^{2}$ Department of Pharmacy, Jiangxi University of Traditional Chinese Medicine, Jiangxi 330004, China
}

Corresponding Author Email: *xh14201@ sina.com, †fanhao11@aliyun.com

\begin{abstract}
3,3 '4,4'-tetrachlorobiphenyl (PCB77) is a highly toxic substance that endanger ecological environment and human health. In our study, a novel PCB77 electrochemical sensor based on nano-functionalized electrode and selected aptamer was designed. $\beta$-cyclodextrin-Au nanoparticles ( $\beta$-CD-AuNPs)/Nafion modified glassy carbon electrode (GCE) was used for amplify signal that enable sensitivity advanced, and the selected electroactive ferrocene $(F c)$ labed aptamer was assembled on the electrode surface via the host-guest recognition between $\beta$ $C D$ and Fc. The detection was carried out according to the signal changed caused by transformation in the configuration of aptamer before and after the existence of PCB77. By this strategy, a detection limit down to 1.6×10-8 g/L was achieved. Moreover, it exhibited reliable selectivity against co-existing chemicals.
\end{abstract}

Keywords: electrochemical, aptasensor, nano-functionalized, 3,3'4,4'-tetrachlorobiphenyl

Received: January-15-2020, Accepted: March-15-2020, https://doi.org/10.14447/jnmes.v23i2.a02

\section{INTRODUCTION}

Synthetic polychlorinated biphenyls (PCBs) are chemically stable and have been widely used in the electricity industry, plastics processing industry, chemical industry, and printing industry. PCBs can be discharged into environment through wastes, leakages, and volatilization during the process of production and use, and stable existence, it is involved in surface circulation, and then accumulates in organisms and human bodies through the food chain [1-2]. Only a low dose of PCBs exposure will cause liver damage, nervousl and endocrine disorders, immunosuppression, reproduction abnormality, and infant dysplasia [3-4]. The International Agency for Research on Cancer (IARC) has classified PCBs as "possible carcinogens in humans" and "carcinogens known to animals". PCB77 is a kind of non-ortho substituted coplanar resemble dioxin $\mathrm{PCB}$, it has the most significant impact on the ecological environment and human health, and more higher toxic than other homologues [5]. Therefore, the content detection of PCB77 is of great significance to assess the environmental risk and human exposure of PCBs.

The traditional detection methods of PCBs include fluorescence spectroscopy [6], chromatography/mass spectrometry (GC/MS) [7], liquid chromatography/mass spectrometry (LC/MS) [8], ect. These above methods have some difficulties to meet the requirements of on-site detection of PCBs pollutants in physical environment because of the high cost of instruments, the complexity of sample processing and the highly trained technicians [9-10]. So far, some immunoassays for PCBs analysis are widely applied, such as enzyme linked immunosorbent assay (ELISA) [11] and antibody-based immunoassay [12], Although these methods have avoided the defects of the traditional methods and have a low detection limit, antibody acquire complicated, poor stabilit, and sensitive to environmental changes, thus, exploring some new sensitive, rapid and convenient methods for spot detection of PCBs is quite essential.

Aptamers are single-strand oligonucleotide that screened by SELEX for specifically bind proteins, small molecules, and inorganic ions. The appearance of aptamers make up for the deficiency of the existing antibodies, except for strict recognition and high affinity with target molecules, aptamers also have the advantages of high stability, nonimmunogenicity, easy to modify, and extensive ligands, and others that antibodies do not possess [13], making aptamers popular among in environmental monitoring [14], pharmaceutical analysis [15], and pathological diagnosis [16].

In recent years, using electrochemical technology and aptamer recognition technology to jointly construct electrochemical aptasensor for the detection of PCBs have been developed [17]. The electrochemical aptasensor can transform the changes that occur after specific binding of the sensitive element and the target into a measurable signal through signal converter, by this way, quantitative detection can be realized. Due to the advantages of low-cost, sensitive, rapid, at the same time, with the high specificity of aptamer recognition, the electrochemical aptasensor have attracted the deep attention of relevant researchers [18-19]. A PCB77 electrochemical sensor based DNA-aptamer was developed in Wu's group [20], the electron transfer of the Fc label on the electrode surface enabled the detection signal to be converted from "off" to "on", and achieved a low detection limit of 0.01 $\mu \mathrm{g} / \mathrm{L}-1$. In addition, $\beta$-cyclodextrin $(\beta-\mathrm{CD})$ is a king of ring molecule connected by multiple D- $\beta$ Pyran glucose units through $\alpha-1,4$ glucosidic bond, with its conical cylindrical ring structure, showing typical internal hydrophobicity and external hydrophilicity. This inner hydrophobic cavity can be used as a perfect supermolecular host, allowing $\beta-C D$ has excellent inclusion capacity for guest molecule [21-22]. By utilizing $\beta$-cyclodextrin polymer ( $\beta$-CDP)/Reduced graphene 
oxide (rGO) hybrid system, an electrochemical sensor for PCBs sensitive detection was constructed in this sensing approach [23], the key point was that PCBs have more higher affinity towards $\beta$-CDP compared to $\mathrm{Fc}$, which provided some ideas for our detection of PCB77 in a certain degree.

Herein, an electrochemical aptasensor was designed for PCB77 detection based nano-functionalized electrode and selected aptamer (Figure 1). Because of the nanometer scale of AuNPs, it possesses excellent physical, chemical properties, such as high electron density, large surface area and ideal dielectric performance, for it can improve the sensitivity of modified electrode to a large extent, that get widely applied [24-25]. We modified the GCE surface with $\beta$-CDAuNPs/Nafion firstly, the Fc- aptamer which selected by SELEX (Systematic Evolution of Ligands by Exponential Enrichment) was acted as probe for signal identification. In the absence of PB77, the aptamer probe maintained single hairpin structure and a large signal appeared because of the redox of Fc on electrode surface, however, due to the specific combination of aptamer probe and PCB77, the structure of aptamer was transformed into a stem-ring structure and away from electrode surface with the appearance of PCB77, which result the obstruction of electronic transmission and the weaken of signal. The influence of nano-functionalized electrode made the detection sensitivity greatly improved with a fine linear calibration range from $0.04 \mu \mathrm{g} / \mathrm{L}$ to $4000 \mu \mathrm{g} / \mathrm{L}$ of PCB77 concentrations. In the meanwhile, the preparation of the electrochemical sensor was simple and easy to operate, it can be seen that can meet rapid and sensitive field detection of PCB77.
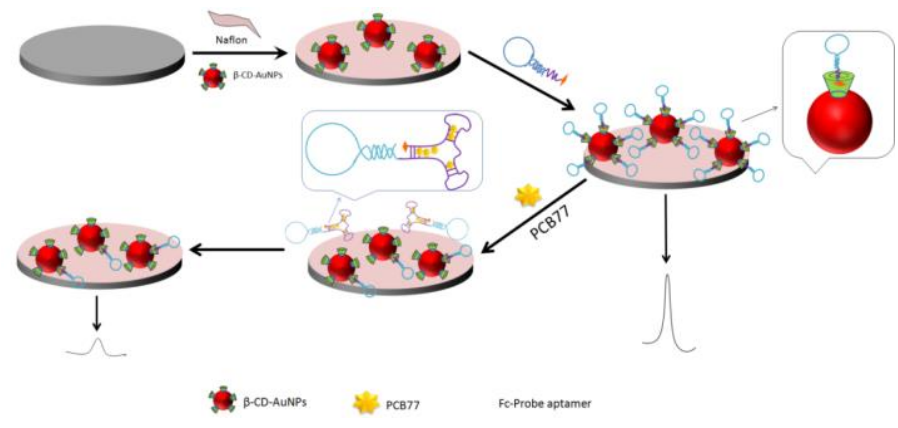

Figure 1. The schematic of PCB77 electrochemical sensor that based on nano-functionalized electrode and selected aptamer

\section{EXPERIMENTAL SECTION}

\subsection{Materials and reagents}

$\begin{array}{cl}\text { Fc-labeled } & \text { aptamer }\end{array}$ probe
GGCGGGGCTACGAAGTAGTGATTTTTTCCGATGGCC CGTG-Fc was synthesized by Takara Co. Ltd (Dalian, China). Polychlorinated biphenyls of 3,3',4,4'-PCB (PCB77), 3,4,4',5-PCB (PCB81), 3,3', 4, 4',5-PCB (PCB126), $3,3^{\prime}, 4,4^{\prime}, 5,5^{\prime}-\mathrm{PCB}$ (PCB169) and 2,3,3',4,4',5,5'-PCB (PCB189) were purchased from Cambridge Isotope Laboratories Inc (USA). A series of PCB77 standard solutions can be obtained by stepwise dilution with the solution of $\mathrm{H}_{2} \mathrm{O}$ and dimethylformamide ( $/ \mathrm{v}=4: 1)$. Unless otherwise specified, the required reagents like dimethylsulfoxide (DMSO), sodium borohydride $\left(\mathrm{NaBH}_{4}\right)$ and acetonitrile $\left(\mathrm{CH}_{3} \mathrm{CN}\right)$ were analytical-reagent grade from Dingguo Biotechnology Inc and all the experimental water was prepared with ultrapure water from Millipore Milli-Q (U.S.A).

\subsection{Apparatus}

The electrochemical measurements were conducted on an autolab electrochemical workstation (Metrohm Instruments Co., Swiss). A three-electrode system for electrochemical experiments recorded: GCE (diameter of $2.0 \mathrm{~mm}$ ) as working electrode, $\mathrm{Ag} / \mathrm{AgCl}$ electrode (saturated $\mathrm{KCl}$ ) as reference electrode and a Pt wire served as counter electrode. The Nuclear Magnetic Resonance Spectrometer-Bruker 400MHZ (Swiss), scanning electron microscopy (SEM) (FEI, America) was used.

\subsection{Preparation of $\beta-C D-A u N P s / N a f i o n$}

Per-6-thio- $\beta$-cyclodextrin (SH- $\beta-\mathrm{CD})$ was synthesized firstly according to the literature [26], then $20 \mathrm{~mL}$ of $\mathrm{HAuCl}_{4}$ $(0.6 \mathrm{mM})$ in DMSO: $\mathrm{H}_{2} \mathrm{O}(\mathrm{v} / \mathrm{v}=4: 1)$ was quickly mixed with 16 $\mathrm{mL}$ of DMSO containing $8.0 \mathrm{mg} \mathrm{SH}-\beta-\mathrm{CD}$ and $60.4 \mathrm{mg}$ $\mathrm{NaBH}_{4}$, the mixed solution was stirred uniformly at room temperature for at least $24 \mathrm{~h}$. Subsequently, the precipitates obtained after the addition of $\mathrm{CH}_{3} \mathrm{CN}$ with $32 \mathrm{~mL}$ were centrifuged and collected, the collected precipitates were added to $50 \mathrm{~mL}$ of $\mathrm{CH}_{3} \mathrm{CN}$ :DMSO (v/v =1:1) and $50 \mathrm{~mL}$ of ethanol for centrifugation washing, respectively, and the $\beta$ CD-AuNPs was prepared by drying the sample overnight under $60{ }^{\circ} \mathrm{C}$ vacuum. The SEM technology was applied to characterize the particle size of obtained $\beta$-CD-AuNPs (Fig. 2).

By mixing the above prepared $\beta$-CD-AuNPs with $0.5 \%$ Nafion and suffered sonication for $30 \mathrm{~min}, \beta-\mathrm{CD}$ AuNPs/Nafion was obtained.

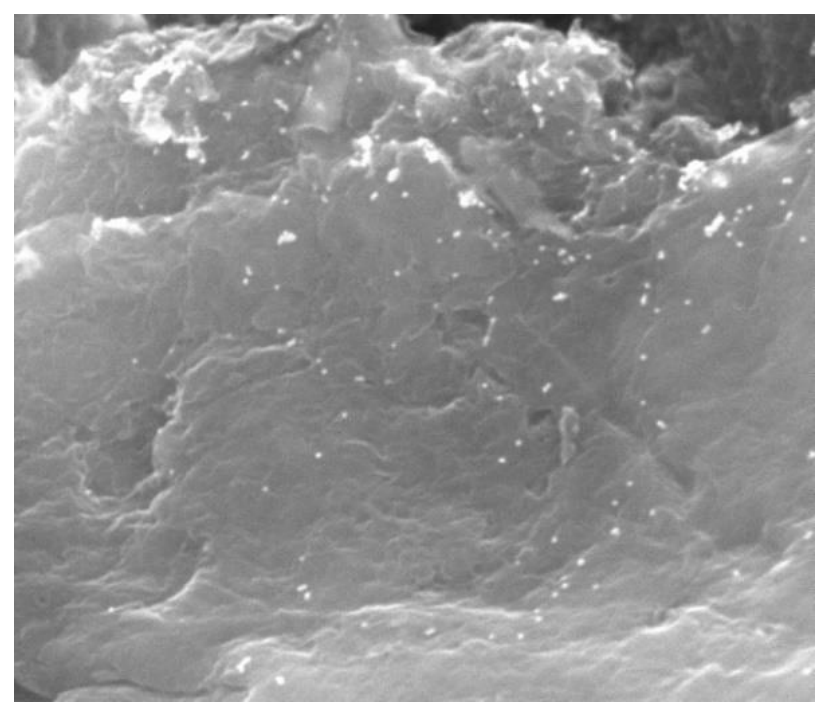

Figure 2. SEM image of the prepared $\beta-C D-A u N P s$

\subsection{Assembly of the electrochemical sensor}

GCE was polished with $0.3-\mu \mathrm{m}$ and $0.05-\mu \mathrm{m}$ alumina slurry respectively and rinsed thoroughly with water. By using microsyringe to spin-coat the GCE with $5 \mu \mathrm{L}$ of $\beta$-CDAuNPs/Nafion, $\beta$-CD-AuNPs/Nafion modified nanofunctionalized electrode was gained after drying at room temperature. In order to complete the assembly of the electrochemical sensor, the $\beta$-CD-AuNPs/Nafion/GCE was 
dipped in $0.3 \mathrm{~mL}$ of Fc-aptamers $(0.1 \mathrm{mM})$ solution for $60 \mathrm{~min}$, and the resulting electrode was eluted thoroughly with $10 \mathrm{mM}$ PBS (pH 7.4).

\subsection{Electrochemical Sensing performance}

The prepared sensor was immersed in $10 \mathrm{mM}$ PBS (pH 7.4) and potential scan was performed by differential pulse voltammetry (DPV), the appeared peak value of signal was recorded as $\mathrm{I}_{1}$. Then a constant concentration of PCB77 in 100 $\mathrm{m} \mathrm{L}$ of $10 \mathrm{mM}$ PBS ( $\mathrm{pH} 7.4$ ) was incubated with the sensor for $45 \mathrm{~min}$, similarly, recording the signal value as $\mathrm{I}_{2}$. Thus, the quantitative analysis of PCB77 was realized via the decreased signal intensity $\left(\Delta \mathrm{I}=\mathrm{I}_{1}-\mathrm{I}_{2}\right)$.

\section{RESULTS AND DISCUSSION}

\subsection{The DPV response of the modified electrode}

The differential pulse voltammetry was used for electrochemical potential response of different electrode (Fig. 3 ). As expected, just like bare GCE, there was no current signal around $0.2 \mathrm{~V}$ on $\beta-\mathrm{CD} / \mathrm{AuNPs} / \mathrm{Nafion}$ modified electrode because of without electron transfer (Fig. 3 curve a). The hostguest recognition effect of $\beta-\mathrm{CD}$ and $\mathrm{Fc}$ brought the Fc-labeled aptamer probe to the electrode surface, after assembling the $\mathrm{Fc}$-aptamer to the $\beta$-CD/AuNPs/Nafion/GCE, the electron transfer of electroactive ferrocene on electrode surface enabled the assembled electrode appeared a large signal value of 1.28 $\mu \mathrm{A}$ (Fig. 3 curve b), which indicating that a considerable number of aptamer probes were immobilized on the electrode surface. However, a decreased signal was appeared compared to the signal response of curve b (Figure 3 curve c) after treating the $\mathrm{Fc}$-aptamer/ $/ \mathrm{CD} / \mathrm{AuNP} / \mathrm{Nafion} / \mathrm{GCE}$ with $4.0 \times 10^{-7} \mathrm{~g} / \mathrm{L}$ PCB77, because the specific combination of aptamer probe and PCB77 allowed some of the aptamer probes left electrode surface, causing a decreased signal that is matched with the concentration of PCB77.

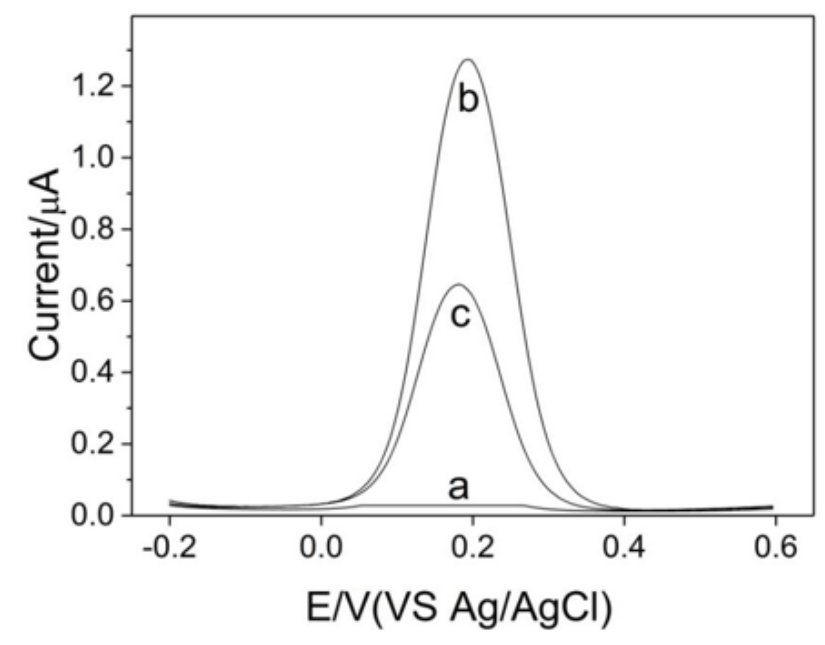

Figure 3. DPV responses of different electrode (Scanning rate: $0.002 \mathrm{~V} / \mathrm{S}$; scanning range: $-0.2 \mathrm{~V} \sim 0.6 \mathrm{~V}$ ) (a) $\beta$ CD/AuNPs/Nafion/GCE, (b) Fc-aptamer/ $\beta$ -

CD/AuNPs/Nafion/GCE, (c) After the Treatment of Fcaptamer/ $\beta$-CD/AuNPs/Nafion/GCE with $4.0 \times 10^{-7} \mathrm{~g} / \mathrm{L}$ PCB77

\subsection{Electrochemical impedance characterization of the modified electrode}

In order to character the process of electrode monitoring, the electrochemical impedance spectroscopy (EIS) was carried out. Showing in Figure 4, only the $\beta-\mathrm{CD} / \mathrm{AuNPs} / \mathrm{Nafion}$ modified electrode displayed a small semicircle with the impedance value of $400 \Omega$ (Fig. 4 curve a), which was similar to the DPV response. When assembled the Fc-aptamer probe to the $\beta-\mathrm{CD} / \mathrm{AuNP} / \mathrm{Nafion} / \mathrm{GCE}$, a large semicircle showed and the impedance increased to $1380 \Omega$ (Fig. 4 curve b), the reason for the sharp increased impedance was that the negative charges between the Fc-aptamer probe and the electrode surface repelled each other, the electron transfer of $\left[\mathrm{Fe}(\mathrm{CN})_{6}\right]$ ${ }^{4-} /{ }^{-}$on the electrode surface was restricted, in the meanwhile, indicating the success of electrode assembly. After exposing Fc-aptamer/ $\beta$-CD/AuNPs/Nafion/GCE with $4.0 \times 10^{-7} \mathrm{~g} / \mathrm{L}$ PCB77, parts of the aptamer probes left electrode surface, the electron transfer rate on the electrode surface recovered to some extent, leading to a slightly decrease in impedance (Fig. 4 curve c).

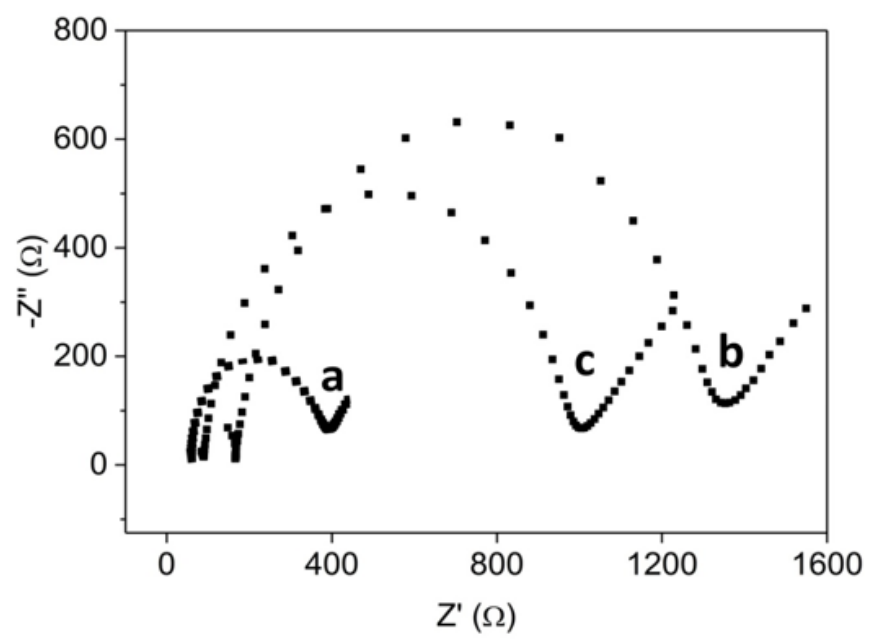

Figure 4. Electrochemical impedance characterization in the process of electrode monitoring (The electrolyte is $5 \mathrm{mmol} / \mathrm{L}$ $\mathrm{K}_{3}\left[\mathrm{Fe}(\mathrm{CN})_{6}\right] / \mathrm{K}_{4}\left[\mathrm{Fe}(\mathrm{CN})_{6}\right]$ containing $\left.0.1 \mathrm{~mol} / \mathrm{L} \mathrm{KCl}\right)$ (a) $\beta$ $\mathrm{CD} / \mathrm{AuNPs} / \mathrm{Nafion} / \mathrm{GCE}$, (b) Fc-aptamer/ $\beta$ -

$\mathrm{CD} / \mathrm{AuNPs} / \mathrm{Nafion} / \mathrm{GCE}$, (c) after the treatment of Fcaptamer/B-CD/AuNPs/Nafion/GCE with $4.0 \times 10^{-7} \mathrm{~g} / \mathrm{L}$ PCB77

\subsection{Optimization of PCB77 incubation time}

In order to enable the detection method to be performed under optimal condition, the detection time of PCB77 was evaluated. When the same concentration of PCB77 was incubated with different time, it was found that as time went by, the signal response value was reduced until $45 \mathrm{~min}$, followed with longer incubation time, the signal no longer diminished and exhibited a stable line, indicating that $45 \mathrm{~min}$ was the best incubation time. And the same was true for other fixed concentrations of PCB77.

\subsection{Analytical performance of the PCB77 sensor}

By incubating the sensor with a series of different concentrations of PCB77, the quantitative behavior of the method was assessed. As the concentration of PCB77 increased, the more probes away from the electrode surface, as 
showed in Figure 5 (left), resulting in a corresponding decrease in the signal values from 1.1 to $0.1 \mu \mathrm{A}(\mathrm{a} \rightarrow \mathrm{f})$. Linear regression analysis of the response signal revealed a negative correlation between the concentration of PCB77 in the range from $4.0 \times 10^{-8} \mathrm{~g} / \mathrm{L}$ to $4.0 \times 10^{-3} \mathrm{~g} / \mathrm{L}$ and the current signal (Figure 5 (right)). The linear curve represented that a regression equation of $\mathrm{y}=-0.194 \log \mathrm{x}-0.3353$ with a correlation coefficient of $\mathrm{R}^{2}=0.994$, and the limit of detection was $1.6 \times 10^{-8} \mathrm{~g} / \mathrm{L}$.
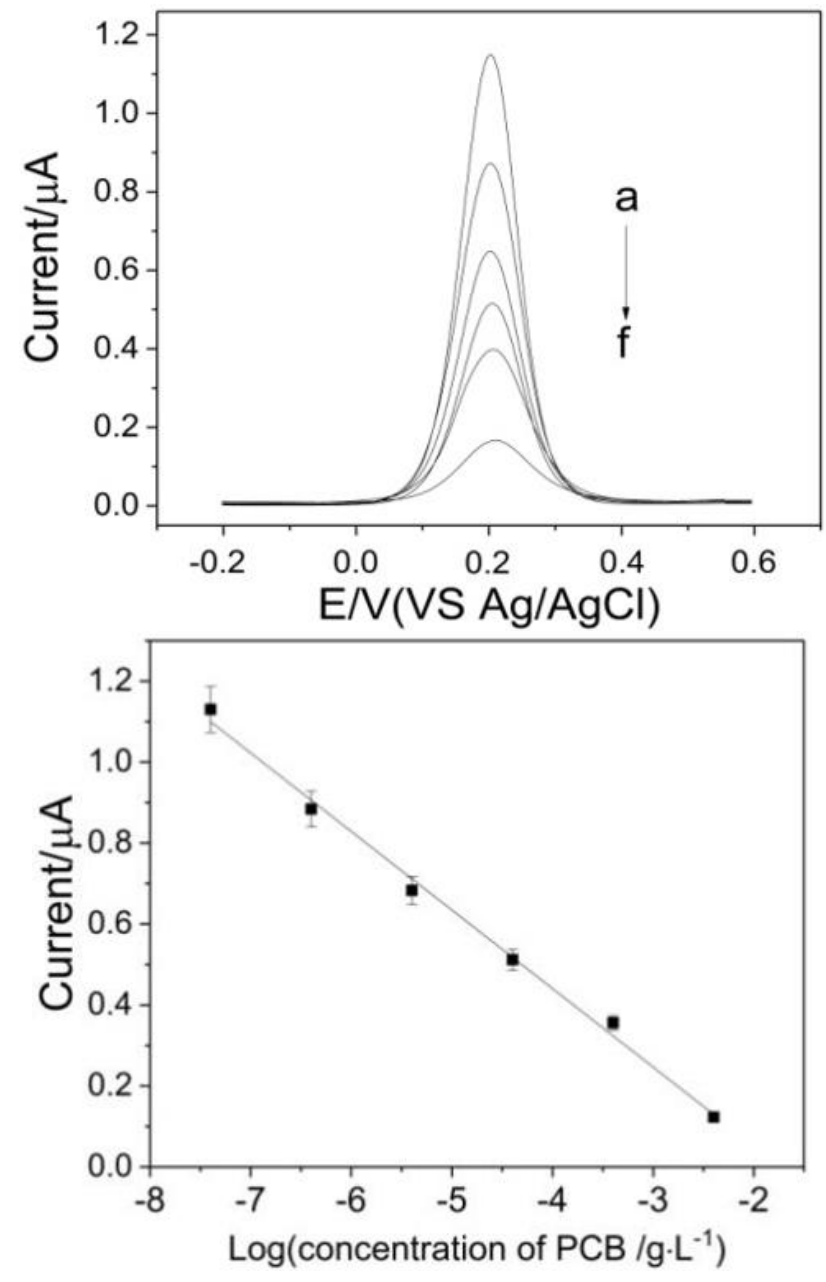

Figure 5. (Left) DPV responses of different PCB77 concentrations. (Right) Calibration curve of PCB77

\subsection{Selectivity of the PCB77 sensor}

Figure 6 showed the response of the sensor to other coplanar PCBs, a decrease percentage in the signal represented the selectivity result. The toxic equivalency factor (TEF) of PCB77, PCB81, PCB126 and PCB169, PCB189 are 0.0001, $0.0001,0.1,0.01$ and 0.0001 , respectively, as the facts showed, there was no established relationship between the signal decrease percentage and TEF at the same concentration of $4.0 \times 10^{-6} \mathrm{~g} / \mathrm{L}$. However, the signal decrease percentages of PCB81, PCB126 and PCB169 can match well with its octanol: water partition coefficients (logKow) (which are 6.42, 6.96, 7.49 and 7.72, respectively) at same concentration, seen in Fig. 6 , with the increase of logKow of PCBs, the signal decrease percentages were strengthened correspondingly expect for PCB77, which can be used as a basis for detecting PCB77 among in co-planar PCBs.

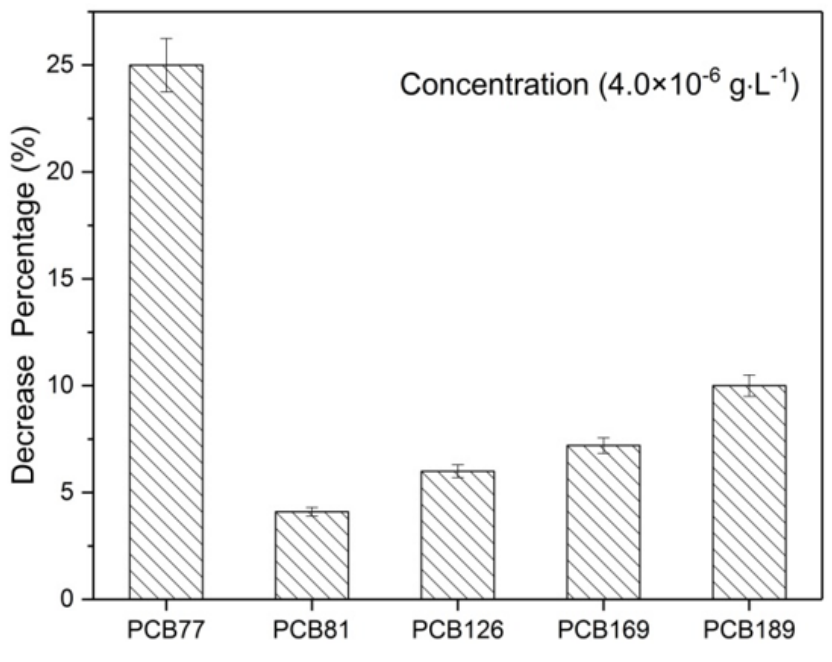

Figure 6. Selectivity of the assay for the detection of PCB77 among in PCB analogs: Organisms concentration was maintained at $4.0 \times 10^{-6} \mathrm{~g} / \mathrm{L}$

\section{CONCLUSION}

In summary, a novel PCB77 electrochemical sensor on the basis of nano-functionalized electrode and selected aptamer was developed. With the signal amplification of nanocomposite, the detection sensitivity greatly improved. It also can meet selective detection of PCB77 among in coexisting chemicals. What's more, the preparation of the electrochemical sensor was simple, all the reactions took place on the modified GCE surface without extra separation procedure. Thus, it will be a sensitive and simple tool for PCB77 field detection.

\section{ACKNOWLEDGEMENT}

This work was kindly supported by the National Natural Science Foundation of China (Grant No.: 81660658 and 81560625), Jiangxi Science and Technology Committee Foundation (Grant No.: 20161BAB215212).

\section{REFERENCES}

[1] Ahmed, F.E. (2003). Analysis of polychlorinated biphenyls in food products. TrAC Trends in Analytical Chemistry, 22(3): https://doi.org/10.1016/S0165-9936(03)00305-4

[2] Gandhi, N., Bhavsar, S.P., Reiner, E.J., Chen, T., Morse, D., Arhonditsis, G.B., Drouillard, K.G. (2015). Evaluation and interconversion of various indicator PCB schemes for $\sum$ PCB and dioxin-like PCB toxic equivalent levels in fish. Environmental Science \& Technology, $49(1)$ : https://doi.org/10.1021/es503427r

[3] Hamers, T., Kamstra, J.H., Cenijn, P.H., Pencikova, K., Palkova, L., Simeckova, P., Vondracek, J., Andersson, P.L., Stenberg, M., Machala, M. (2011). In vitro toxicity profiling of ultrapure non-dioxin-like polychlorinated biphenyl congeners and their relative toxic contribution to PCB mixtures in humans. Toxicological Sciences, 121(1): 88-100. https://doi.org/10.1093/toxsci/kfr043 
[4] Martinez, A., Hornbuckle, K.C. (2011). Record of PCB congeners, sorbents and potential toxicity in core samples in Indiana Harbor and Ship Canal. Chemosphere, 85(3): 542-547. https://doi.org/10.1016/j.chemosphere.2011.08.018

[5] Van den Berg, M., Birnbaum, L., Bosveld, A.T., Brunström, B., Cook, P., Feeley, M., Giesy, J.P., Hanberg, A., Hasegawa, R., Kennedy, S.W., Kubiak, T., Larsen, J.C., Leeuwen, F.X.V., Liem, A.K., Nolt, C., Peterson, R.E., Poellinger, L., Safe, S., Schrenk, D., Tillitt, D., Tysklind, M., Younes, M., Waern, F., Zacharewski, T. (1998). Toxic equivalency factors (TEFs) for PCBs, PCDDs, PCDFs for humans and wildlife. Environmental health perspectives, 106(12): 775-792. ttps://doi.org/10.1289/ehp.98106775

[6] Wang, M., Meng, G., Huang, Q., Li, M., Li, Z., Tang, C. (2011). Fluorescence detection of trace PCB101 based on PITC immobilized on porous AAO membrane. Analyst, 136(2): 278-281. https://doi.org/10.1039/C0AN00510J

[7] Yang, W., Yu, Z. Q., Luo, X.F., Feng, J.L., Zhang, D.P., Ren, G.F., Sheng, G.Y., Fu, J.M. (2012). Qualitative analysis of some emerging halogenous pollutions in fish sample by comprehensive two-dimensional gas chromatography/time-of-flight mass spectrometry. Chinese Journal of Analytical Chemistry, 40(8): $1187-$ 1193. https://doi.org/10.1016/S1872-2040(11)60564-1

[8] Focant, J.F., Cochran, J.W., Dimandja, J.M.D., DePauw, E., Sjödin, A., Turner, W.E., Patterson Jr, D.G. (2004). High-throughput analysis of human serum for selected polychlorinated biphenyls (PCBs) by gas chromatography-isotope dilution time-of-flight mass spectrometry (GC-IDTOFMS). Analyst, 129(4): 331336. https://doi.org/10.1039/B313675B

[9] West, C., Lesellier, E. (2008). A unified classification of stationary phases for packed column supercritical fluid chromatography. Journal of Chromatography A, 1191(12): 21-39. https://doi.org/10.1016/j.chroma.2008.02.108

[10] Zhang, L.H., Wu, X.Z. (2007). Capillary electrophoresis with in-capillary solid-phase extraction sample cleanup. Analytical chemistry, 79(6): 2562-2569. https://doi.org/10.1021/ac0621591

[11] Fillmann, G., Galloway, T.S., Sanger, R.C., Depledge, M.H., Readman, J.W. (2002). Relative performance of immunochemical (enzyme-linked immunosorbent assay) and gas chromatography-electron-capture detection techniques to quantify polychlorinated biphenyls in mussel tissues. Analytica Chimica Acta, 461(1): 75-84. https://doi.org/10.1016/S0003-2670(02)00233-7

[12] Terakado, S., Ohmura, N., Park, S.U., Lee, S.M., Glass, T.R. (2013). New Antibody and Immunoassay Pretreatment Strategy to Screen Polychlorinated Biphenyls in Korean Transformer Oil. Analytical Sciences, 29(10): 963-969. https://doi.org/10.2116/analsci.29.963

[13] Huang, K.J., Liu, Y.J., Cao, J.T., Wang, H.B. (2014). An aptamer electrochemical assay for sensitive detection of immunoglobulin E based on tungsten disulfide-graphene composites and gold nanoparticles. RSC Advances, 4(69): 36742-36748. https://doi.org/10.1039/C4RA06133K

[14] Lu, Y., Huang, Q., Meng, G., Wu, L.,Zhang, J. (2014). Label-free selective SERS detection of PCB-77 based on DNA aptamer modified $\mathrm{SiO} 2 @ \mathrm{Au}$ core/shell nanoparticles. Analyst, 139(12): 3087.https://doi.org/10.1039/C4AN00197D

$3083-$

[15] Yu, Z.G., Sutlief, A.L., Lai, R.Y. (2018). Towards the development of a sensitive and selective electrochemical aptamer-based ampicillin sensor. Sensors and Actuators $\begin{array}{lll}\text { B: } & \text { Chemical, } & \text { 258: }\end{array}$ https://doi.org/10.1016/j.snb.2017.11.193

[16] Chen, C., Wei, G., Yao, X., Liao, F., Peng, H., Zhang, J., Hong, N., Fan, H. (2018). Ru (bpy)32+/ $\beta$-cyclodextrin$\mathrm{Au}$ nanoparticles/nanographene functionalized nanocomposites-based thrombin electrochemiluminescence aptasensor. Journal of Solid State Electrochemistry, 22(7), 2059-2066. https://doi.org/10.1007/s10008-018-3910-6

[17] Mascini, M. (2001). Affinity electrochemical biosensors for pollution control. Pure and Applied Chemistry, 73(1): 23-30. https://doi.org/10.1351/pac200173010023

[18] Lin, Y., Cheng, L., Wei, G.B., He, L.L., Chen, C.D., De, R.K., Peng, H., Fan, H. (2017). Reagentless, 2lectrochemical aptasensor for lead (II) detection. Journal of New Materials for Electrochemical Systems, 20(1): 1-5. https://doi.org/10.14447/jnmes.v20i1.286

[19] Beiranvand, S., Azadbakht, A. (2017). Electrochemical switching with a DNA aptamer-based electrochemical sensor. Materials Science and Engineering: C, 76: 925933. https://doi.org/10.1016/j.msec.2017.03.028

[20] Wu, L., Qi, P., Fu, X., Liu, H., Li, J., Wang, Q., Fan, H. (2016). A novel electrochemical PCB77-binding DNA aptamer biosensor for selective detection of PCB77. Journal of Electroanalytical Chemistry, 771: 45-49. https://doi.org/10.1016/j.jelechem.2016.04.003

[21] Bouhadiba, A., Belhocine, Y., Rahim, M., Djilani, I., Nouar, L., Khatmi, D.E. (2017). Host-guest interaction between tyrosine and $\beta$-cyclodextrin: Molecular modeling and nuclear studies. Journal of Molecular Liquids, 233: 358-363. https://doi.org/10.1016/j.molliq.2017.03.029

[22] Vogt, F.G., Strohmeier, M. (2012). 2D solid-state NMR analysis of inclusion in drug-cyclodextrin complexes. Molecular pharmaceutics, 9(11): 3357-3374. https://doi.org/10.1021/mp300416w

[23] Zheng, X., Li, H., Xia, F., Tian, D., Hua, X., Qiao, X., Zhou, C. (2016). An electrochemical sensor for ultrasensitive determination the polychlorinated biphenyls. Electrochimica Acta, 194: 413-421. https://doi.org/10.1016/j.electacta.2016.02.115

[24] Cheng, R., Liu, S., Shi, H., Zhao, G. (2018). A highly sensitive and selective aptamer-based colorimetric sensor for the rapid detection of PCB 77. Journal of hazardous materials, 341: 373-380. https://doi.org/10.1016/j.jhazmat.2017.07.057

[25] Xu, S., Yuan, H., Chen, S., Xu, A., Wang, J., Wu, L. (2012). Selection of DNA aptamers against polychlorinated biphenyls as potential biorecognition elements for environmental analysis. Analytical Biochemistry, 423(2): 195-201. https://doi.org/10.1016/j.ab.2012.01.026

[26] Ha, W., Kang, Y., Peng, S.L., Ding, L.S., Zhang, S., Li, B.J. (2013). Vesicular gold assemblies based on hostguest inclusion and its controllable release of doxorubicin. Nanotechnology, 24(49): 495103. https://doi.org/10.1088/0957-4484/24/49/495103 